\title{
Light sensitivity of Haberlea rhodopensis shade adapted phenotype under
}

\section{drought stress}

Katya Georgieva ${ }^{1}$, Ádam Solti ${ }^{2}$, Ilona Mészáros ${ }^{3}$, Áron Keresztes ${ }^{4}$, Éva Sárvári ${ }^{2}$

${ }^{1}$ Institute of Plant Physiology and Genetics, Bulgarian Academy of Sciences, Acad. G. Bonchev Str., B1. 21, BG-1113 Sofia, Bulgaria

${ }^{2}$ Department of Plant Physiology and Molecular Plant Biology, Institute of Biology, Eötvös Loránd University, Pázmány P. sétány 1/C, H-1117 Budapest, Hungary

3 Department of Botany, Institute of Biology and Ecology, Faculty of Sciences and Technology, University of Debrecen, P.O. Box: 14 Debrecen, 4010, Hungary

${ }^{4}$ Department of Plant Anatomy, Institute of Biology, Eötvös Loránd University, Pázmány P. sétány 1/C, H-1117 Budapest, Hungary

Corresponding author: Katya Georgieva, Institute of Plant Physiology and Genetics,

Bulgarian Academy of Sciences, Sofia, Bulgaria. Tel. 35929792620 . Fax 35928739952.

E-mail katya@bio21.bas.bg; katyamg@yahoo.com 
Abstract Haberlea rhodopensis belongs to the group of homoiochlorophyllous desiccation tolerant plants which preserve their chlorophyll content during dehydration. It is a typical shade adapted plant and it is proved to be very sensitive to light intensity higher than the natural during drought stress. To reveal the reasons of their light sensitivity, we compared the damages and protective mechanisms of shade plants during desiccation either simulating their natural light conditions ( $30 \mu \mathrm{mol}$ photons $\left.\mathrm{m}^{-2} \mathrm{~s}^{-1}, \mathrm{LL}\right)$ or at a moderately higher light intensity (100 $\mu \mathrm{mol}$ photons $\mathrm{m}^{-2} \mathrm{~s}^{-1}$, ML). In the desiccated stage, no damage could be discovered in terms of thylakoid membrane quantity or integrity either at LL or ML. Nevertheless, the altered structure and localization of chloroplasts did not restore in plants desiccated and rehydrated at ML, where no starch could be re-synthesized but a number of plastoglobuli appeared. The PSII activity and the amount of $\beta$-carotene and lutein decreased more strongly in ML leaves in agreement with their higher MDA production. Lack of recovery of ML plants may be connected with the very high number of damaged PSII reaction centers caused by the loss of the subtle balance between ROS production and scavenging. In addition, because of the impaired starch re-synthesis, there is no sink for the water-replacing sugars and water cannot be taken up which proved to be lethal to ML plants.

Key words Desiccation tolerance · Photoinhibition - Chloroplast structure - Carotenoids · Excitation energy allocation

\section{Introduction}

Desiccation-tolerant or resurrection plants are excellent model systems for studying the cellular and molecular mechanisms underlying tolerance against extreme drought. They are able to survive desiccation to air-dry state and to resume full physiological activities after 
rehydration. Upon drying, angiosperm tissues must be protected against a number of stresses brought about by or in association with extreme water loss. The irradiation during desiccation can be extremely damaging to photosynthetically active tissues (Sherwin and Farrant 1998). Under light conditions, desiccation increases the production of singlet oxygen, inducing oxidative stress (Farrant et al. 2003; Dinakar and Bartels 2012). Deleterious effects of free radicals on biological structures include DNA nicking, oxidation of proteins, and peroxidation of membrane lipids (Asada 1999).

Each desiccation tolerant plant species have evolved different protective mechanisms to overcome the photooxidative damages (Moore et al. 2009). Poikilochlorophyllous resurrection plants lose their chlorophyll and thylakoid membranes are dismantled during dehydration, what has been suggested to be a protective mechanism to prevent photooxidation under conditions when photosynthesis is not possible (Sherwin and Farrant 1998; Tuba et al. 1998). Homoiochlorophyllous resurrection plants have alternative mechanisms to prevent photooxidation or are able to repair photooxidation-related damage. Resurrection plants can avoid excess light by leaf movements, folding of the leaves, accumulation of protective pigments, together with enzymatic and non-enzymatic antioxidants (Farrant 2000; Neill et al. 2002; Dinakar et al. 2012).

Physiological properties of the photosynthetic apparatus are of crucial importance in desiccation-tolerant plants. The photosynthetic apparatus is very sensitive and liable to injuries, and needs to be maintained or quickly repaired upon rehydration (Ramanjulu and Bartels 2002). Drought stress is known to inhibit photosynthetic activity in tissues due to an imbalance between light capture and its utilization (Foyer and Noctor 2000). During desiccation, quenchers accumulate which are stable in the absence of water but revert to nonquenching molecular species on hydration (Heber at al. 2006). Together with zeaxanthin- 
dependent energy dissipation, desiccation-induced thermal energy dissipation protects desiccated plants against photo-oxidation during water loss and in the desiccated state.

Haberlea rhodopensis (Gesneriaceae) is a resurrection plant of temperate climate, originating from the Balkan Peninsula as an endemic and relict species of the Tertiary period. From an ecological point of view, $H$. rhodopensis is a perennial, herbaceous species belonging to the group of homoiochlorophyllous poikilohydric plants which preserve their chlorophyll content during dehydration. Both the more common low irradiation (shade) adapted plants and the recently dicovered highhigh irradiation adapted plants of $H$. rhodopensis growing on rocks directly exposed to sunlight (Daskalova et al. 2011) were shown to recover similarly from desiccated stage (Rapparini et al. 2015). In contrast, though shade plants were able to survive desiccation to water content of $<10 \%$ at low irradiance ( 30 $\mu \mathrm{mol}$ photons $\mathrm{m}^{-2} \mathrm{~s}^{-1}$ photosynthetic photon flux density; PPFD) with photosynthetic activity fully recovered after rehydration (Georgieva et al. 2007), they were very sensitive to photoinhibition (Georgieva et al. 2008). Their photosensitivity was proposed to be connected with the disappearance of a dense substance from the thylakoid lumen during desiccation at higher light intensity (Georgieva et al. 2010). The aim of the present study was to reveal some of the reasons for the light sensitivity of $H$. rhodopensis shade adapted plants by assessing and comparing the protective mechanisms during desiccation and rehydration at low $(30 \mu \mathrm{mol}$ photons $\mathrm{m}^{-2} \mathrm{~s}^{-1}$ PPFD) or moderate $\left(100 \mu \mathrm{mol}\right.$ photons $\mathrm{m}^{-2} \mathrm{~s}^{-1}$ PPFD) irradiation.

\section{Materials and methods}

\section{Plant material, desiccation and rehydration}


Well-hydrated Haberlea rhodopensis Friv. plants were collected from their natural habitat (Helleno-Carpatho-Balkanic siliceous cliff vegetation) in the Rhodope Mountains where they grow on the rock surfaces in deep shade below the tree canopy at light intensity of 20-30 $\mu \mathrm{mol}$ photons $\mathrm{m}^{-2} \mathrm{~s}^{-1}$ PPFD at the natural habitat. Adult rosettes of similar size were selected for the experiments. The tufts with their natural substrate (thin soil layer) were planted in peat-soil and transferred into a growth chamber, where plants were kept at $22-23{ }^{\circ} \mathrm{C}$ and relative humidity of $60 \%$. As for treatments, two growth irradiances: $30 \mu \mathrm{mol}$ photons $\mathrm{m}^{-2} \mathrm{~s}^{-1}$ PPFD (LL) and $100 \mu \mathrm{mol}$ photons $\mathrm{m}^{-2} \mathrm{~s}^{-1}$ PPFD (ML), both with 12/12 $\mathrm{h}$ day/night cycles were applied. After 10 days of acclimation to the light intensity of the treatments, plants were subjected to drought stress by ceasing watering up to air-dry stage. Desiccated plants were rehydrated by spraying water on the leaves to simulate rainfall and keeping the soil moist. Leaf sampling and measurements were conducted after 2 days (stage D1; RWC about $70 \%$ ), 4 days (stage D2; RWC about $25 \%$ ) and 7 days of dehydration (stage D3; RWC about $6 \%$ ), as well as after 1 day and 7 days of rehydration (stages R1 and R7, respectively). Control plants kept either at 30 or $100 \mu \mathrm{mol}$ photons $\mathrm{m}^{-2} \mathrm{~s}^{-1}$ PPFD were regularly watered throughout the experiment. Mature but not old leaves of similar developmental stage were chosen during the whole period of the experiment. The different parameters were measured taking samples of the same leaf or the same group of leaves depending on the amount of sample needed.

\section{Electron microscopy}

Leaf pieces taken from the middle portion of two mature leaves in each stage were fixed in $2.5 \%$ glutaraldehyde (65 mM K-Na phosphate buffer, $\mathrm{pH} 7.2$ ) for $2 \mathrm{~h}$ at room temperature. After thorough washing with the above buffer, they were post-fixed in $1 \%$ OsO4 for $1.5 \mathrm{~h}$, followed by dehydration in an ethanol series. Samples were embedded in Durcupan ACM, 
sectioned with a Reichert-Jung Ultracut E ultramicrotome (on three grids from both leaves per stage), and then stained with uranyl acetate and lead citrate. The sections were examined in a Hitachi 7100 (Hitachi Ltd, Tokyo, Japan) electron microscope. Micrographs were taken with a MegaView III camera (Soft Imaging System, Münster, Germany).

\section{Determination of the malondialdehyde content}

50-100 mg leaf material was homogenized with $500 \mu \mathrm{l} 0.1 \%$ trichloroacetic acid (TCA). Samples were kept on ice until centrifugation at $10000 \times \mathrm{g}$ for $10 \mathrm{~min}$ at $4{ }^{\circ} \mathrm{C}$. One $\mathrm{ml}$ MDA reagent ( $20 \%$ TCA, $1.0 \%$ thiobarbituric acid) was added to $250 \mu 1$ supernatant. After $30 \mathrm{~min}$ incubation at $100{ }^{\circ} \mathrm{C}$, samples were cooled and examined spectrophotometrically at $532 \mathrm{~nm}$ at room temperature (Heath and Packer 1968). MDA values were calculated on a dry weight basis using the extinction coefficient of $155 \mathrm{mM}^{-1} \mathrm{~cm}^{-1}$.

\section{Determination of the carotenoid content}

For the determination of xanthophyll cycle components, leaf discs were kept in the dark or irradiated with $100 \mu \mathrm{mol} \mathrm{m} \mathrm{m}^{-2} \mathrm{~s}^{-1}$ PPFD for 30 minutes. Other carotenoids were determined from both dark and irradiated samples. Leaf discs were powdered in liquid nitrogen and extracted with $80 \%(\mathrm{v} / \mathrm{v})$ acetone containing $0.1 \%(\mathrm{v} / \mathrm{v}) \mathrm{NH}_{4} \mathrm{OH}$ at $4{ }^{\circ} \mathrm{C}$. Carotenoid components were separated by a HPLC method (Goodwin and Britton 1988) using a Nucleosil C18 column in HPLC-system equipped with an UV/VIS detector (JASCO Int. Co., Japan), and acetonitrile:water mixture $(9: 1,0.01 \%(\mathrm{v} / \mathrm{v})$ triethylamine $)$ and ethyl acetate as eluents. Zeaxanthin standard was used for identification of peaks and calculation of pigment concentrations (Tóth et al. 2002). The de-epoxidation state of xanthophyll cycle pigments 
(DEPS) was calculated as $(\mathrm{Z}+0.5 \mathrm{~A}) /(\mathrm{V}+\mathrm{A}+\mathrm{Z})$, where $\mathrm{V}, \mathrm{A}$, and $\mathrm{Z}$ are violaxanthin, antheraxanthin and zeaxanthin, respectively.

\section{Fluorescence induction measurement, quenching analysis}

Fluorescence induction measurements were carried out with intact leaves using PAM 101102-103 Chlorophyll $a$ Fluorometer (Walz, Effeltrich, Germany). Leaves were dark-adapted for $30 \mathrm{~min}$. The $F_{o}$ level of fluorescence was determined by switching on the measuring light (modulation frequency of $1.6 \mathrm{kHz}$, less than $1 \mu \mathrm{mol}$ photon $\mathrm{m}^{-2} \mathrm{~s}^{-1}$ PPFD after $3 \mathrm{~s}$ illumination with far-red light in order to eliminate reduced electron carriers (Belkhodja et al. 1998). The maximum fluorescence yields, $F_{m}$ in the dark-adapted state and $F_{m}{ }^{\prime}$ in light-adapted state, were measured by applying a $0.7 \mathrm{~s}$ pulse of white light (PPFD of $3500 \mu \mathrm{mol}$ photon $\mathrm{m}^{-2} \mathrm{~s}^{-1}$, light source: KL 1500 electronic, Schott, Mainz, Germany). For quenching analysis, actinic white light (PPFD of $100 \mu \mathrm{mol}$ photon $\mathrm{m}^{-2} \mathrm{~s}^{-1}$, KL 1500 electronic) was provided. Simultaneously with the onset of actinic light the modulation frequency was switched to 100 $\mathrm{kHz}$. The steady-state fluorescence of light-adapted state $\left(F_{s}\right)$ was determined when no change was found in $F_{m}{ }^{\prime}$ values between two white light flashes separated by $100 \mathrm{~s}$. For assessing the excitation energy allocation in all samples, the quenching parameters of Hendrickson et al. (2005) were used:

$$
\begin{aligned}
& \Phi_{P S I I}=\left(1-\frac{F_{s}}{F_{m}^{\prime}}\right) *\left(\frac{F_{v} / F_{m}}{F_{v M} / F_{m M}}\right) ; \\
& \Phi_{N P Q}=\left(\frac{F_{s}}{F_{m}^{\prime}}-\frac{F_{s}}{F_{m}}\right) *\left(\frac{F_{v} / F_{m}}{F_{v M} / F_{m M}}\right) ; \\
& \Phi_{f, D}=\frac{F_{s}}{F_{m}} *\left(\frac{F_{v} / F_{m}}{F_{v M} / F_{m M}}\right) ; \\
& \Phi_{N F}=1-\frac{F_{v} / F_{m}}{F_{v M} / F_{m M}},
\end{aligned}
$$


where the total absorbed excitation energy, $\Sigma \mathrm{E}_{\mathrm{exc}}=\Phi_{\mathrm{PSII}}+\Phi_{\mathrm{NPQ}}+\Phi_{\mathrm{f}, \mathrm{D}}+\Phi_{\mathrm{NF}}=1$ and $\Phi_{\mathrm{PSII}}$ is the quantum yield of photochemistry; $\Phi_{\mathrm{NPQ}}$ is the quantum yield of light dependent and $\Delta \mathrm{pH}$ - and xanthophyll-mediated regulated thermal dissipation; $\Phi_{\mathrm{f}, \mathrm{D}}$ is the combined quantum efficiency of fluorescence and constitutive, light-independent thermal dissipation; and $\Phi_{\mathrm{NF}}$ is the quantum yield of thermal dissipation in inactivated, non-functional PSIIs. $F_{v M} / F_{m M}$ was applied as the mean of quasi non-inhibited (fully hydrated plants) $F_{v} / F_{m}$ values according to Solti et al. (2014). Since the normalisation method of the excitation energy allocation is based on quasi non-inhibited 'controls', the differences in the PSII maximum quantum efficiencies indicate the fraction of inactivated PSII reaction centres by any reasons in the treated plants (eg. Solti et al., 2014; Solti et al., 2016a, Solti et al., 2016b). The intensity of actinic light was low enough not to cause additional inactivation of PSII centres, i.e. changing the basis of normalisation (Haberlea rhodopensis high irradiation adapted plants) caused no increase in the $\Phi_{\mathrm{NF}}$ parameter (Solti Á, unpublished results), thus $\Phi_{\mathrm{NF}}$ can be considered the fraction of PSII reaction centres inactivated under the desiccation process.

\section{Statistical analysis}

For each sample at least three measurements were performed on fully expanded mature leaves collected from different plants. Comparison of means was made by the Fisher least significant difference (LSD) test at $\mathrm{P} \leq 0.05$ following ANOVA. A statistical software package (StatGraphics Plus, version 5.1 for Windows, USA) was used.

\section{Results}


The decrease in RWC of Haberlea leaves during dehydration under low or medium light irradiance was very similar. The leaves were dehydrated to about $70 \%$ (stage D1) and $25 \%$ RWC (stage D2) after 2 and 4 days, respectively, and they were nearly fully desiccated after 7 days (6 \% RWC, stage D3). Following rewatering, plants desiccated at LL regained most of their water content very rapidly, within $24 \mathrm{~h}$ (about $70 \% \mathrm{RWC}$, stage R1), and were completely rehydrated after 7 days (about $90 \%$ RWC, stage R7). However, despite of some transient rise in the RWC of plants desiccated at ML after 1 day of rehydration (17\% RWC), their RWC was only $10 \%$ of the corresponding control in stage R7. Exposure of well-watered (control) H. rhodopensis plants to ML did not influence the leaf water content.

Electron microscopy of control, desiccated and rehydrated H. rhodopensis shade leaves revealed changes in the location, shape and inner structure of chloroplasts during the treatment (Fig. 1). Control chloroplasts showed normal structure, containing a little more starch in ML plants (Fig. 1a, b). In the desiccated stage, when the chloroplasts became roundish, and re-localized into the inside of the cell, the starch grains completely disappeared from the LL plastids, while a few of them occasionally remained in the ML plastids. The thylakoids were arranged more or less concentrically, but no damage could be discovered in terms of thylakoid membrane quantity or integrity either at LL or ML (Fig. 1c, d). However, the control structure and localization of chloroplasts did not recover in plants desiccated and rehydrated at ML, where no starch could be re-synthesized (in contrast to the LL plastids), but a number of plastoglobuli appeared (Fig. 1e, f).

Dehydration of $H$. rhodopensis leaves to around $25 \%$ RWC (D2 stage) doubled the amount of MDA (Fig. 2). ML plants had even higher MDA content, which was about $35 \%$ higher compared to LL plants. MDA levels remained relatively high in the fully dehydrated stage (D3) and they were higher than the controls in both LL and ML plants after the recovery period (R7). 
Dehydration to about $70 \%$ RWC (D1) did not influence the carotenoid content calculated on a dry weight basis, while the $\beta$-carotene and lutein contents were strongly reduced both in D2 and D3 stages (Fig 3a, b) similarly to the amount of the total carotenoids (not shown). The levels of neoxanthin and VAZ did not change significantly, though VAZ content showed a slightly increasing trend during the desiccation of ML plants (Fig 3c, d). Recovery of the carotenoid contents was only observed in LL plants. At the same time, the level of carotenoids on a total Chl basis did not change significantly, except a slight trend of increase in the VAZ content in ML leaves during the desiccation period (Fig. S1).

The light and dark de-epoxidation indices changed characteristically during the treatments (Fig. 4). In light-adapted stage, the de-epoxidation index was similar in LL and ML leaves. During dehydration of LL plants, de-epoxidation of violaxanthin was slightly elevated only in D2 stages, whereas it increased during desiccation and also after rehydration of ML plants (Fig. 4a). In dark-adapted stage, however, the de-epoxidation index increased gradually both in LL and ML leaves as they lost water, and in ML leaves even after rehydration in contrast to LL leaves where it recovered (Fig. 4b).

In agreement with the changes observed in the dark de-epoxidation indices, larger darkstable de-epoxidated carotenoid pools were built up during desiccation starting from the D1and D2 stage in ML and LL plants, respectively (Fig. S2). Moreover, further elevation of the pool was found during rehydration of ML plants.

Excitation energy allocation changed markedly during desiccation and rehydration but the trend of changes was different in LL and ML treated leaves (Fig. 5a, b). Quantum yield of PSII photochemistry $\left(\Phi_{\mathrm{PSII}}\right)$ strongly decreased in D2 stage and was zero in D3 after desiccation at both LL and ML. While it recovered almost totally after one day rehydration in LL plants, only some transient rise was observed in their ML counterparts. The combined quantum efficiency of fluorescence and constitutive thermal dissipation $\left(\Phi_{f, D}\right)$ increased in D2 
stage in the leaves of both LL and ML plants, and in ML plants during rehydration (Fig. 5a, b). It decreased after total desiccation (D3 stage) compared to D2 stage, more strongly in ML plants. $\Phi_{\mathrm{NPQ}}$, the quantum yield of light dependent and $\Delta \mathrm{pH}-$ and xanthophyll-mediated regulated thermal dissipation, strongly decreased under severe desiccation (D3 stage), and recovered in rehydrated leaves of LL but showed only transient increase in ML plants. Light minus dark de-epoxidation indices (light induced de-epoxidation) changed more or less in parallel to those of $\Phi_{\mathrm{NPQ}}$ (Fig. 5c, d). The quantum yield of thermal dissipation in nonfunctional PSII ( $\left.\Phi_{\mathrm{NF}}\right)$ was antiparallel to those of $\Phi_{\mathrm{PSII}}$ : it was high in strongly dehydrated stages of leaves in both LL and ML plants, and also in the R1 and R7 stages of ML leaves.

\section{Discussion}

Homoiochlorophyllous resurrection plants, which maintain their photosynthetic apparatus during desiccation, are able to regulate photosynthetic activity and protect the photosynthetic apparatus during water loss (Toldi et al. 2009). Shade and sun adapted plants of $H$. rhodopensis did not differ markedly in their photosynthetic machinery (Sárvári et al. 2014), both could recover from desiccated stage at their natural environment (Rapparini et al. 2015). However, the shade adapted plants proved to be very sensitive to higher than the natural light intensity during drought stress (Georgieva et al. 2008). To reveal the reasons of their light sensitivity, we compared the damages and protective mechanisms of shade plants during desiccation either simulating their natural light conditions (30 $\mu \mathrm{mol}$ photons $\mathrm{m}^{-2} \mathrm{~s}^{-1}$ PPFD) or at a moderately higher light intensity $\left(100 \mu \mathrm{mol}\right.$ photons $\mathrm{m}^{-2} \mathrm{~s}^{-1}$ PPFD) which is generally tolerated by the well-hydrated plants (Georgieva et al. 2010).

Desiccation and rehydration induced significant changes in the structure and function of mesophyll cells in shade populations of $H$. rhodopensis, (Georgieva et al. 2007, 2010). 
Though ML treatment did not influence the photosynthetic activity of $H$. rhodopensis plants in fully hydrated stage (Georgieva et al. 2010), PSII activity declined more strongly in ML treated plants during dehydration which did not recovered upon rewatering, in contrast to LL plants (Fig. 5). Loss of photosynthetic performance was accompanied by a proportional elevation in the MDA content due to the production of reactive oxygen species (Das and Roychoudhury 2014). MDA content was the highest in D2 stage under both light conditions, but higher in ML than in LL plants. Thus, stronger lipid peroxidation, determined as increased MDA accumulation in ML plants during desiccation, indicate the incapability of recovery.

Though the ROS production was quite low due to the abundant protective mechanisms in H. rhodopensis plants (Gechev et al. 2013), the transient production of ROS during the water loss and possibly also under rehydration might result in damages of the photosynthetic apparatus. A part of protein complexes were decomposed in both LL and ML thylakoids as reflected by the reduction in their chlorophyll (Georgieva et al. 2010) and carotenoid contents (Fig. 3). However, the latter was nearly unchanged on a chlorophyll basis due to the similar extent of reduction of chlorophyll and carotenoids. Particularly, the amount of $\beta$-carotene and lutein decreased owing to the decomposition of PSII complexes (Sárvári et al. 2014; Mihailova et al. 2011), and more strongly in ML leaves in agreement with their higher MDA production.

Most of the oxidative damages are connected to the malfunction of the photosynthetic apparatus under water deficit (Lawlor and Cornic 2002). In addition to the different protective mechanisms and substances detected in H. rhodopensis plants (Yahubyan et al. 2009; Georgieva et al. 2010; Djilianov et al. 2011; Apostolova et al. 2012; Gechev et al. 2013), alteration in the excitation energy allocation were also found to contribute to the protection of the photosynthetic apparatus during water loss in both in LL and ML plants. Among the quenching processes working in the antennae, $\Phi_{\mathrm{NPQ}}$, the quantum yield of the energization 
(and thus xanthophyll cycle) dependent thermal dissipation proved to be the most important in plants with active photosynthesis. The elimination of $\Phi_{\mathrm{NPQ}}$ in the terminal stage of desiccation showed similarities to the results obtained in the sister-taxon of H. rhodopensis, Ramonda serbica (Augusti et al. 2001). The parallel changes in the light-inducible de-epoxidation of the xanthophyll pool to $\Phi_{\mathrm{NPQ}}$, and the increase in the amount of illumination-insensitive pool in the ML leaves upon rehydration together indicated that only the light-sensitive pool is involved in the xanthophyll cycle coupled regulated quenching of excitation energy. This is in agreement with the earlier findings that only a part of zeaxanthin pool was needed for NPQ in Quercus coccifera (Peguero-Pina et al. 2013). The decrease in the $\Phi_{\mathrm{NPQ}}$ was stronger in ML plants, thus in D2 stage, the reduced capability for antenna quenching could also lead to damages in the PSII. Therefore, ML plants suffered from larger damage during the desiccation, also shown by the higher PSII inactivation $\left(\Phi_{\mathrm{NF}}\right)$. Damages occurring during the desiccation may have significant consequences for the capability of recovery.

In addition to the light-inducible zeaxanthin pool, the sustained zeaxanthin pool was also found generally important in the stress protection of desiccation tolerant species, such as mosses (Heber et al. 2001) and some tracheophytes (Casper et al. 1993; García-Plazaola et al. 2012). Various functions of zeaxanthin have been shown: (i) de-epoxidated carotenoids, particularly zeaxanthin bound to the monomeric Lhcb4-6 antenna components of PSII and the Lhca1-4 subunits of PSI at the L2 site that modulates chlorophyll triplet formation, and thereby prevents the production of singlet oxygen (Dall'Osto et al. 2012), (ii) zeaxanthin bound to the V1 site of LHCII (Caffarri et al. 2001) contributes to the qI component of NPQ (Horton et al. 2005), (iii) binding of zeaxanthin to Lhc proteins strongly decreases the excited singlet state lifetime of antenna chlorophylls (Gilmore et al. 1998) thus lowering the probability of energy transfer to the reaction centre, (iv) some zeaxanthin localised in the lipid phase of the thylakoids (Dall'Osto et al. 2010) or in the chloroplast envelope (Douce et al. 
1973) has a distinct capacity among xanthophylls in quenching of ROS (Havaux et al. 2007) produced either inside or outside of the chloroplasts. In the long term, zeaxanthin induces monomerization and degradation of the major LHCII antenna complex, thus further reducing the over-excitation of PSII (Havaux et al. 2004). This type of reorganization was also found in desiccating H. rhodopensis (Sárvári et al. 2014). In addition to zeaxanthin, neoxanthin, the amount of which was stable during dehydration in both LL and ML plants, may be also involved in the protection of dehydrating $H$. rhodopensis plants against photooxidation (Dall'Osto et al. 2007; Mozzo et al. 2008). However, such carotenoid based protective mechanisms were not enough in ML plants for their survival.

Protective functional changes were observed not only in the antenna but also in the reaction centre part of PSII. The quantum yield of thermal dissipation related to nonfunctional PSII $\left(\Phi_{\mathrm{NF}}\right)$, i.e. the transformation of inactivated PSII to heat sinks (Chow et al. 2002), was already triggered by a small RWC decrease (Strasser et al. 2010; Solti et al. 2014). $\Phi_{\mathrm{NF}}$ increased markedly with severe water loss, more strongly in ML plants (Fig. 4), in contrast to its behaviour in sun compared to shade plants (Rapparini et al. 2015). Decrease in $\Phi_{\mathrm{NPQ}}$ and the increase in $\Phi_{\mathrm{NF}}$ refers to a change in the protective mechanisms in thylakoids of LL and ML plants as the water content became lower, and the activity of xanthophyll cycle was ceasing. Higher proportion of $\Phi_{\mathrm{NF}}$ in desiccated ML plants refers to more inactivated PSII centres, which may be in connection with their only transient recovery.

Upon rehydration, only a transient recovery was observed in ML plants (Fig. 5a, b). While in R1 stage, the recovery of PSII function started together with a significant increase in the $\Phi_{\mathrm{NPQ}}$, this process turned back, and the excitation energy allocation profile in R7 was more similar to that in the desiccated stage referring to the loss of photosynthetic activity. PSII inactivation was significantly higher in the R1 stage of ML plants compared to that of LL plants, which refers to more severe damage of the PSII RCs during desiccation in ML 
plants. Sun et al. (2006) showed that if PSII RCs are inactivated by strong light exposure, they may recover, but for the recovery, a small residual functional PSII population was critical. Comparing the PSII damages in sun and shade plants, it seems that the shade ones are at the threshold of survival during desiccation (Rapparini et al. 2015). From our present results, it can be also concluded that ML plants are probably under this tentative threshold of survival.

ML chloroplasts not only did not recover from desiccated stage but numerous plastoglobuli appeared in them. As the prominent component of these lipid droplets is the antioxidant tocopherol (Vidi et al. 2006; Piller et al. 2014), their large increase in number could be connected with the higher ROS production caused by the concomitant desiccation and rehydration under light stress. Although both shade and sun adapted thylakoids contain ample protective luminal substance (DLS) during a dehydration-rehydration cycle (Sárvári et al. 2014; Georgieva et al. 2015), ML thylakoids run out of this (probably phenolic) substance (visible at high resolution) during desiccation (Georgieva et al. 2010). The non-eliminated ROS species may damage not only the thylakoid membrane components (PSII RCs), but also inhibit starch re-synthesis during rehydration (Fig. 1f). The reason may be either the lack of ATP synthesis caused by inhibition of photosynthetic electron transport, or the impaired starch synthase activity, or inhibited triose transport across the plastid envelope. In such a way there is no sink for the water-replacing sugars filling the numerous small vacuoles in the desiccated state (Georgieva et al. 2015). Since water can not be taken up by the cells under rewatering, the desiccation proved to be lethal to ML plants.

Summing up, H. rhodopensis plants acclimated to low light environment are not able to survive drought and light co-stress. While xanthophyll cycle activity is the main nonphotochemical quenching mechanism in actively photosynthesizing leaves, quenching by the non-functional PSII reaction centres comes into prominence at low leaf water content. In spite of the higher zeaxanthin-associated protective mechanisms, lack of recovery of ML plants 
may be connected with the very high number of damaged PSII reaction centres and the impaired starch re-synthesis, caused by the loss of the subtle balance between ROS production and scavenging, which arrested the chloroplast structure and the arrangement of the whole cell content in the desiccated stage.

Author contribution statement Katya Georgieva designed the study, measured fluorescence induction and wrote the manuscript. Ádam Solti contributed to fluorescence induction measurements, quenching analysis and statistical analyses. Ilona Mészáros performed carotenoid determinations and calculations. Áron Keresztes carried out electron microscopy studies. Éva Sárvári measured malondialdehyde content and contributed to carotenoid analyses and writing the manuscript. All authors critically reviewed the paper.

\section{Acknowledgement}

Á. Solti, É. Sárvári, Á. Keresztes and K. Georgieva kindly acknowledge the travel exchange agreement of the Bulgarian and Hungarian Academy of Sciences. Á. Solti was also supported by the Bolyai János Research Scholarship of the Hungarian Academy of Sciences (BO/00207/15/4).

\section{References}


Apostolova E, Rashkova M, Anachkov N, Denev I, Toneva V, Minkov I, Yahubyan G (2012) Molecular cloning and characterization of cDNAs of the superoxide dismutase gene family in the resurrection plant Haberlea rhodopensis. Plant Physiol Biochem 55:85-92

Asada K (1999) The water-water cycle in chloroplasts: Scavenging of active oxygen and dissipation of excess photons. Annu Rev Plant Physiol Plant Mol Biol 50:601-639

Augusti A, Scartazza A, Navari-Izzo F, Sgherri CLM, Stevanovic B, Brugnoli E (2001) Photosystem II photochemical efficiency, zeaxanthin and antioxidant contents in the poikilohydric Ramonda serbica during dehydration and rehydration. Photosynth Res $67: 79-88$

Belkhodja R, Morales F, Quílez R, López-Milla'n AF, Abadía A, Abadía J. (1998) Iron deficiency causes changes in chlorophyll fluorescence due to the reduction in the dark of the photosystem II acceptor side. Photosynth Res 56:265-276

Caffarri S, Croce R, Breton J, Bassi R (2001) The major antenna complex of photosystem II has a xanthophyll binding site not involved in light harvesting. J Biol Chem 276:3592435933

Casper C, Eickmeier WG, Osmond CB (1993) Changes of fluorescence and xanthophyll pigments during dehydration in the resurrection plant Selaginella lepidophylla in low and medium light intensities. Oecologia 94:528-533

Chow WS, Lee HY, Park YI, Park YM, Hong YN, Anderson JM (2002) The role of inactive photosystem-II-mediated quenching in a last-ditch community defence against high light stress in vivo. Philosophical Transactions of the Royal Society of London 357B: $1441-1450$

Dall'Osto L, Cazzaniga S, Havaux M, Bassi R (2010) Enhanced photoprotection by proteinbound versus free xanthophyll pools. A comparative analysis of chlorophyll $b$ and xanthophyll biosynthesis mutants. Mol Plant 3:576-593 
Dall'Osto L, Cazzaniga S, North H, Marion-Poll M, Bassi R (2007) The Arabidopsis aba4-1 mutant reveals a specific function for neoxanthin in protection against photooxidative stress. Plant Cell 19:1048-1064

Dall'Osto L, Holt NE, Shanti Kaligotla S, Fuciman M, Cazzaniga S, Carbonera D, Frank HA, Alric J, Bassi R (2012) Zeaxanthin protects plant photosynthesis by modulating chlorophyll triplet yield in specific light-harvesting antenna subunits. J Biol Chem 287:41820-41834

Das K, Roychoudhury A (2014) Reactive oxygen species (ROS) and response of antioxidants as ROS-scavengers during environmental stress in plants. Front Environ Sci 2: article 53

Daskalova E, Dontcheva S, Yahoubian G, Minkov I, Toneva V (2011) A strategy for conservation and investigation of the protected resurrection plant Haberlea rhodopensis Friv. BioRisk 6:41-60

Dinakar C, Bartels D (2012) Light response, oxidative stress management and nucleic acid stability in closely related Linderniaceae species differing in desiccation tolerance. Planta 236:541-555

Dinakar C, Djilianov D, Bartels D (2012) Photosynthesis in desiccation tolerant plants: energy metabolism and antioxidative stress defense. Plant Sci 182:29-41

Djilianov D, Ivanov S, Moyankova D, Miteva L, Kirova E, Alexieva V, Joudi M, Peshev D, Van den Ende W (2011) Sugar ratios, glutathione redox status and phenols in the resurrection species Haberlea rhodopensis and the closely related non-resurrection species Chirita eberhardtii. Plant Biol 13:767-776

Douce R, Holtz RB, Benson AA (1973) Isolation and properties of envelope of spinachchloroplasts. J Biol Chem 248:7215-7222 
Farrant JM (2000) Comparison of mechanisms of desiccation tolerance among three angiosperm resurrection plants. Plant Ecol 151:29-39

Farrant JM, Vander Willigen C, Loffell DA, Bartsch S, Whittaker A (2003) An investigation into the role of light during desiccation of three angiosperm resurrection plants. Plant Cell Environ 26:1275-1286

Foyer C, Noctor G (2000) Oxygen processing in photosynthesis: regulation and signaling. New Phytol 146:359-388

García-Plazaola JI, Esteban R, Fernández-Marín B, Kranner I, Porcar-Castell A (2012) Thermal energy dissipation and xanthophyll cycles beyond the Arabidopsis model. Photosynth Res 113:89-103

Georgieva K, Lenk S, Buschmann C (2008) Responses of the resurrection plant Haberlea rhodopensis to high irradiance. Photosynthetica 46:208-215

Georgieva K, Sárvári É, Keresztes Á (2010) Protection of thylakoids against combined light and drought by a lumenal substance in the resurrection plant Haberlea rhodopensis. Ann Bot 105:117-126

Georgieva K, Szigeti Z, Sárvári É, Gáspár L, Maslenkova L, Peeva V, Peli E, Tuba Z (2007) Photosynthetic activity of homoiochlorophyllous desiccation tolerant plant Haberlea rhodopensis during dehydration and rehydration. Planta 225:955-964

Georgieva K, Rapparini F, Bertazza G, Mihailova G, Sárvári É, Solti Á, Keresztes Á (2015) Alterations in the sugar metabolism and in the vacuolar system of mesophyll cells contribute to the desiccation tolerance of Haberlea rhodopensis ecotypes. DOI $10.1007 / \mathrm{s} 00709-015-0932-0$

Gechev TS, Benina M, Obata T, Tohge T, Sujeeth N, Minkov I, Hille J, Temanni M-R, Marriott AS, Bergström E, Thomas-Oates J, Antonio C, Mueller-Roeber B, Schippers 
JHM, Fernie AR, Toneva V (2013) Molecular mechanisms of desiccation tolerance in the resurrection glacial relic Haberlea rhodopensis. Cell Mol Life Sci 70:689-709

Gilmore A M, Shinkarev V P, Hazlett T L, Govindjee (1998) Quantitative analysis of the effects of intrathylakoid $\mathrm{pH}$ and xanthophyll cycle pigments on chlorophyll $a$ fluorescence lifetime distributions and intensity in thylakoids. Biochemistry 37:1358213593

Goodwin TW, Britton G (1988) Distribution and analysis of carotenoids In: Goodwin TW (ed) Plant Pigments. Academic Press, London, UK, pp 62-132

Havaux M, Dall'osto L, Bassi R (2007) Zeaxanthin has enhanced antioxidant capacity with respect to all other xanthophylls in Arabidopsis leaves and functions independent of binding to PSII antennae. Plant Physiol 145:1506-1520

Havaux M, Dall'Osto L, Cuiné S, Giuliano G, Bassi R (2004) The effect of zeaxanthin as the only xanthophyll on the structure and function of the photosynthetic apparatus in Arabidopsis thaliana. J Biol Chem 279:13878-13888

Heath R, Packer L (1968) Photoperoxidation in isolated chloroplasts. I. Kinetics and stoichiometry of fatty acid peroxidation. Arch Biochem Biophys 125:189-198

Heber U, Bukhov NG, Shuvalov VA, Kobayashi Y, Lange OL (2001) Protection of the photosynthetic apparatus against damage by excessive illumination in homoiohydric leaves and poikilohydric mosses and lichens. J Exp Bot 52:1999-2006

Heber U, Bilger W, Shuvalov V (2006) Thermal energy dissipation in reaction centres and in the antenna of photosystem II protects desiccated poikilohydric mosses against photooxidation. J Exp Bot 57:2993-3006

Hendrickson L, Förster B, Pogson BJ, Chow WS (2005) A simple chlorophyll fluorescence parameter that correlates with the rate coefficient of photoinactivation of Photosystem II. Photosynth Res 84:43-49 
Horton P, Wentworth M, Ruban A (2005). Control of the light harvesting function of chloroplast membranes: the LHCII aggregation model for non-photochemical quenching. FEBS Lett 579:4201-4206

Lawlor DW and Cornic G (2002) Photosynthetic carbon assimilation and associated metabolism in relation to water deficits in higher plants. Plant Cell Environ 25:275-294

Mihailova G, Petkova S, Büchel C, Georgieva K. (2011) Desiccation of the resurrection plant Haberlea rhodopensis at high temperature. Photosynth Res 108:5-13

Moore JP, Le NT, Brandt WF, Driouich A, Farrant JM (2009) Towards a systems-based understanding of plant desiccation tolerance. Trends Plant Sci 14:110-117

Mozzo M, Dall'Osto L, Hienerwadel_R, Bassi R, Croce R (2008) Photoprotection in the antenna complexes of photosystem II. Role of individual xanthophylls in chlorophyll triplet quenching. J Biol Chem 283:6184-6192

Neill SO, Gould KS, Kilmartin PA, Mitchell KA, Markham KR (2002) Antioxidant activities of red versus green leaves in Elatostema rugosum. Plant Cell Environ 25:539-547

Peguero-Pina JJ, Gil-Pelegrín E, Morales F (2013) Three pools of zeaxanthin in Quercus coccifera leaves during light transitions with different roles in rapidly reversible photoprotective energy dissipation and photoprotection. J Exp Bot 64:1649-1661

Piller LE, Glauser G, Kessler F, Besagni C (2014) Role of plastoglobules in metabolite repair in the tocopherol redox cycle. Front Plant Sci 5:298.

Ramanjulu S, Bartels D (2002) Drought- and desiccation-induced modulation of gene expression in plants. Plant Cell Environ 25:141-151

Rapparini F, Neri L, Mihailova G, Petkova S, Georgieva K (2015) Growth irradiance affects the photoprotective mechanisms of the resurrection angiosperm Haberlea rhodopensis Friv. in response to desiccation and rehydration at morphological, physiological and biochemical levels. Environ Exp Bot 113:67-79 
Sárvári É, Mihailova G, Solti Á, Keresztes Á, Velitchkova M, Georgieva K (2014) Comparison of thylakoid structure and organization in sun and shade Haberlea rhodopensis populations under desiccation and rehydration. J Plant Physiol 171:15911600

Sherwin H, J Farrant (1998) Protection mechanisms against excess light in the resurrection plants Craterostigma wilmsii and Xerophyta viscose. Plant Growth Regul 24:203-210

Solti Á, Lenk S, Mihailova G, Mayer P, Barócsi A, Georgieva K (2014) Effects of habitat light conditions on the excitation quenching pathways in desiccating Haberlea rhodopensis leaves: an Intelligent FluoroSensor study. J Photochem Photobiol B 130:217-225

Solti Á, Sárvári É, Szöllősi E, Tóth B, Mészáros I, Fodor F, Szigeti Z (2016a) Stress hardening under long-term cadmium treatment is correlated with the activation of antioxidative defence and iron acquisition of chloroplasts in Populus. Z Naturforsch C $71: 323-334$

Solti Á, Sárvári É, Tóth B, Mészáros I, Fodor F (2016b) Incorporation of iron into chloroplasts triggers the restoration of cadmium induced inhibition of photosynthesis. $\mathrm{J}$ Plant Physiol 202:97-106

Strasser RJ, Tsimilli-Michael M, Qiang S, Goltsev V (2010) Simultaneous in vivo recording of prompt and delayed fluorescence and 820-nm reflection changes during drying and after rehydration of the resurrection plant Haberlea rhodopensis. Biochim Biophys Acta 1797:1313-1326

Sun Z-L, Lee H-L, Matsubara S, Hope AB, Pogson BJ, Hong Y-N, Chow WS (2006) Photoprotection of residual functional photosystem II units that survive illumination in the absence of repair, and their critical role in subsequent recovery. Physiol Plant $128: 415-424$ 
Toldi O, Tuba Z, Scott P (2009) Vegetative desiccation tolerance: Is it a goldmine for bioengineering crops? Plant Sci 176:187-199

Tóth VR, Mészáros I, Veres Sz, Nagy J (2002) Effects of the available nitrogen on the photosynthetic activity and xanthophyll cycle pool of maize in field. J Plant Physiol $159: 627-634$

Tuba Z, Proctor MCF, Csintalan Z (1998) Ecophysiological responses of homoiochlorophyllous and poikilochlorophyllous desiccation-tolerant plants: A comparison and an ecological perspective. Plant Growth Regul 24:211-217

Vidi P-A, Kanwischer M, Baginsky S, Austin JR, Csucs G, Dörmann p, Kessler F, Bréhélin C (2006) Tocopherol cyclase (VTE1) localization and vitamin E accumulation in chloroplast plastoglobule lipoprotein particles. J Biol Chem 281:11225-11234

Yahubyan G, Gozmanova M, Denev I, Toneva V, Minkov I (2009) Prompt response of superoxide dismutase and peroxidase to dehydration and rehydration of the resurrection plant Haberlea rhodopensis. Plant Growth Regul 57:49-56

\section{Figure legends}


Fig. 1 Electron micrographs of leaf cells in control (a, b), desiccated (to D3 stage - about 6\% RWC) (c, d), and rehydrated (for 7 days) (e, f) Haberlea rhodopensis shade plants acclimated and treated at LL (30 $\mu \mathrm{mol}$ photons $\left.\mathrm{m}^{-2} \mathrm{~s}^{-1}, \mathrm{a}, \mathrm{c}, \mathrm{e}\right)$ and ML $\left(100 \mu \mathrm{mol}\right.$ photons $\mathrm{m}^{-2} \mathrm{~s}^{-1}, \mathrm{~b}, \mathrm{~d}$, f). pg - plastoglobuli; s - starch. Scale bars are $5 \mu \mathrm{m}$.

Fig. 2 Changes in the MDA content of H. rhodopensis leaves desiccated and rehydrated at LL (grey) and ML (white), respectively. C - control (90\% RWC); D1/D2/D3 - stages of dehydration to 70/25/6 \% RWC, respectively; R7 - 7 days recovery (90/10 \% RWC in LL/ML leaves). Values are means $\pm \mathrm{SD}(\mathrm{n}=3)$; letters in common within a graph indicate no significant differences assessed by Fisher LSD test $(\mathrm{P} \leq 0.05)$ after performing ANOVA.

Fig. 3 Changes in the carotenoid content of $H$. rhodopensis leaves (expressed in the percentage of the LL control) desiccated and rehydrated at LL (grey) and ML (white), respectively. For explanation of symbols see legend to Fig. 2. LL control values of $\beta$-carotene (a), lutein (b), neoxanthin (c), VAZ (d) are in order: 253.0 $\pm 30.8 ; 776.1 \pm 31.3 ; 131.7 \pm 3.1 ; 148$ $7 \pm 8.7 \mathrm{nmol}$ carotenoid $\mathrm{g}^{-1} \mathrm{DW}$. VAZ - Violaxanthin+Antheraxanthin+Zeaxanthin. Values are means $\pm \mathrm{SD}(\mathrm{n}=6)$; letters in common within a graph indicate no significant differences assessed by Fisher LSD test $(\mathrm{P} \leq 0.05)$ after performing ANOVA.

Fig. 4 Changes in the de-epoxidation indices, $(\mathrm{Z}+0.5 \mathrm{~A}) /(\mathrm{V}+\mathrm{A}+\mathrm{Z})$, determined in light- (a) and dark-adapted (b) H. rhodopensis leaves desiccated and rehydrated at LL (grey) and ML (white). V, A, and Z are violaxanthin, antheraxanthin and zeaxanthin, respectively. For explanation of symbols see legend to Fig. 2. Values are means \pm SD $(n=3)$; letters in common within a graph indicate no significant differences assessed by Fisher LSD test $(\mathrm{P} \leq 0.05)$ after performing ANOVA.

Fig. 5 Changes in the excitation energy allocation $(a, b)$ and the light-induced part of the deepoxidation indices (c, d) determined in H. rhodopensis leaves desiccated and rehydrated at LL (a, c) and ML (b, d), respectively. For explanation of symbols see legend to Fig. 2. Values are means $\pm \mathrm{SD}(\mathrm{n}=5-\mathrm{a}, \mathrm{b}$ and $\mathrm{n}=3-\mathrm{c}, \mathrm{d})$. $\Phi_{\mathrm{PSII}}$ : quantum yield of photochemistry; $\Phi_{\mathrm{NPQ}}$ : quantum yield of light dependent and $\Delta \mathrm{pH}$ - and xanthophyll-mediated regulated thermal dissipation; $\Phi_{\mathrm{f}, \mathrm{D}}$ : combined quantum efficiency of fluorescence and constitutive, lightindependent thermal dissipation; $\Phi_{\mathrm{NF}}$ : quantum yield of thermal dissipation in inactivated, non-functional PSIIs. Letters in common within a graph indicate no significant differences assessed by Fisher LSD test $(\mathrm{P} \leq 0.05)$ after performing ANOVA. 

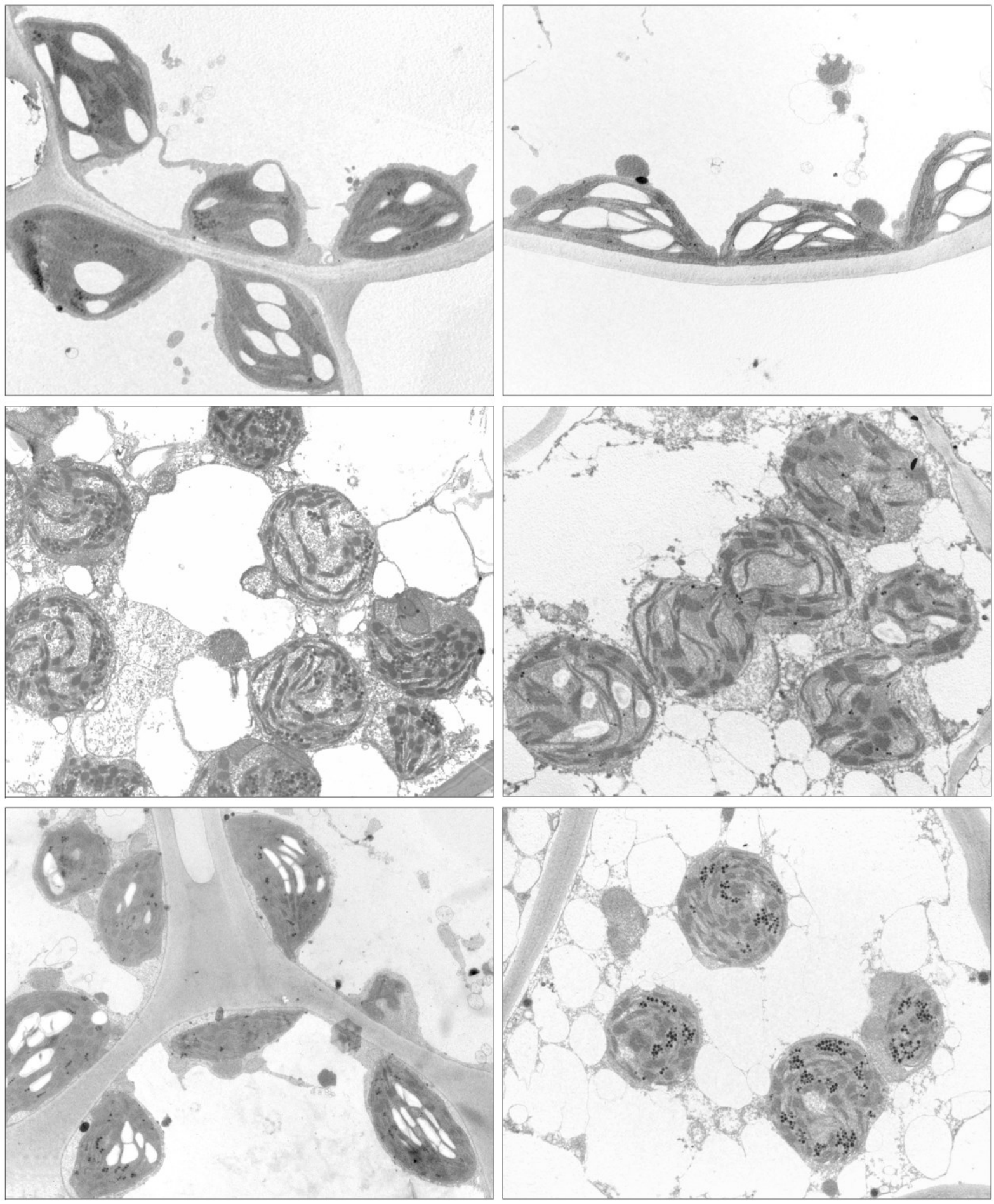

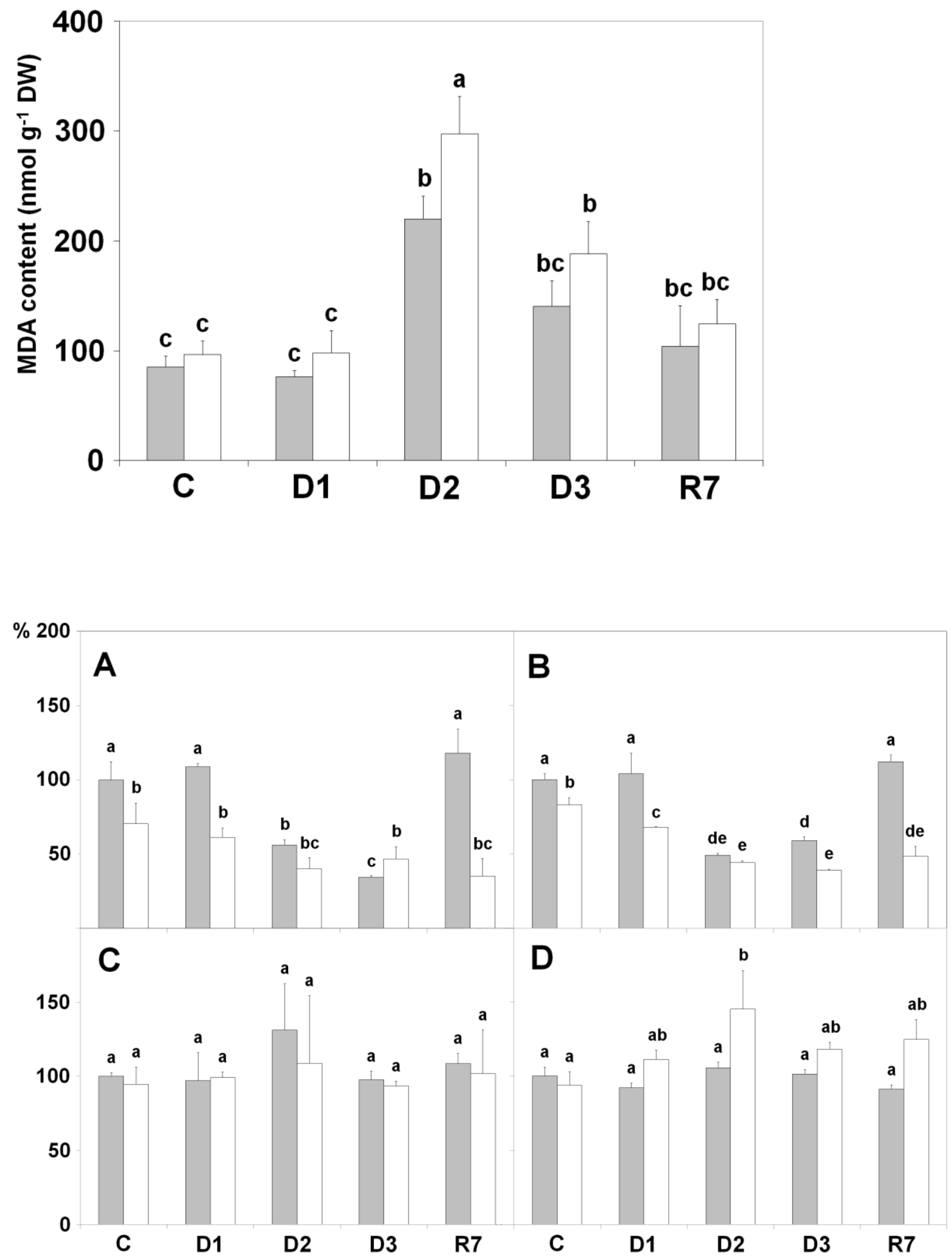

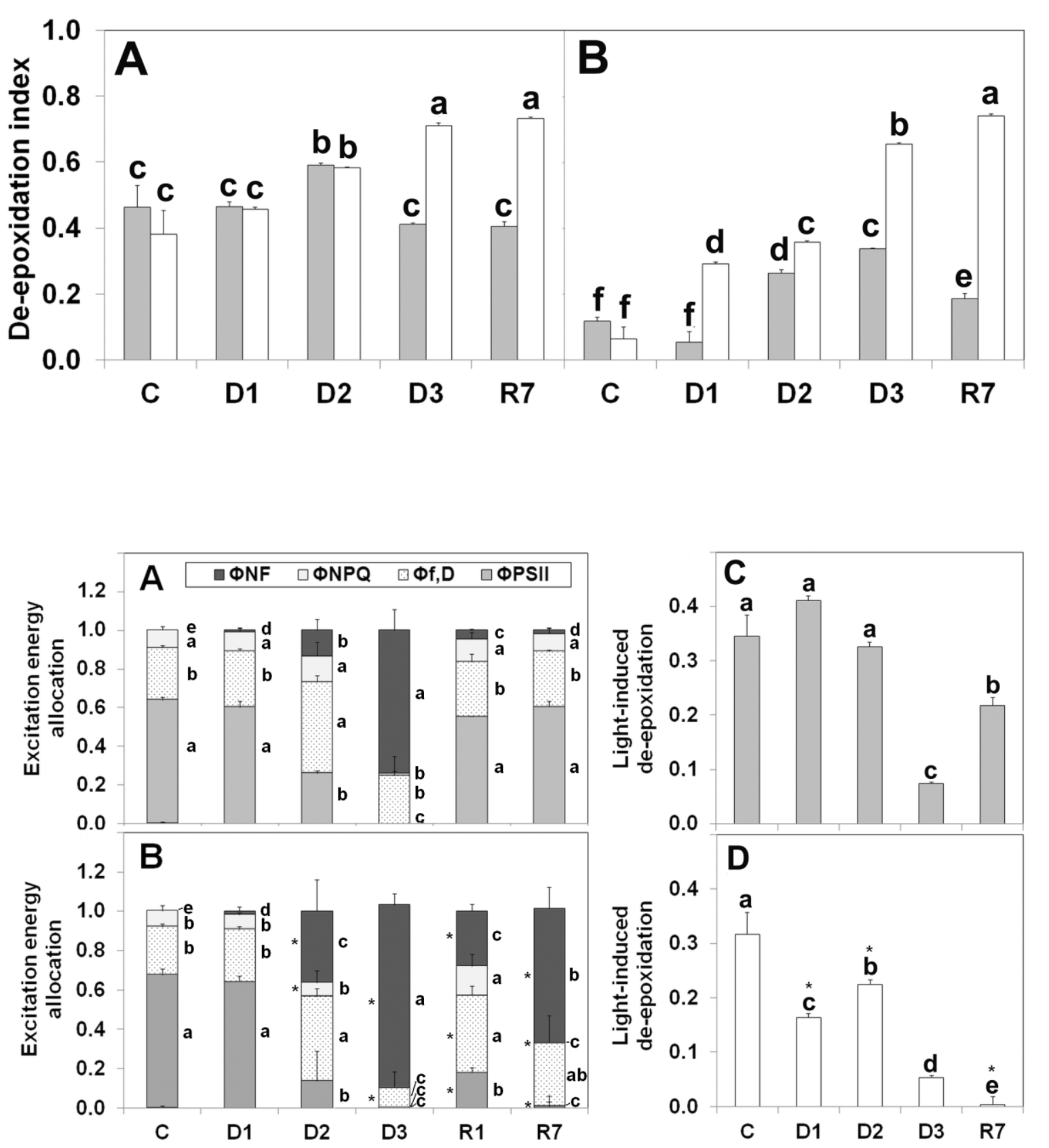